DOI: $10.18027 / 2224-5057-2021-11-3 s 2-32$

Цитирование: Гладков О.А., Зуков Р.А., Матвеев В.Б., Митин Т. (США), Носов Д.А., Попов А.М. Практические рекомендации по лекарственному лечению рака мочевого пузыря. Злокачественные опухоли: Практические рекомендации RUSSCO \#3s2, 2021 (том 11).32

\title{
ПРАКТИЧЕСКИЕ РЕКОМЕНДАЦИИ ПО ЛЕКАРСТВЕННОМУ ЛЕЧЕНИЮ РАКА МОЧЕВОГО ПУЗЫРЯ
}

Коллектив авторов: Гладков О.А., Зуков Р.А., Матвеев В.Б., Митин Т. (США), Носов Д.А., Попов А.М.

Ключевые слова: рак мочевого пузыря, трансуретральная резекция, внутрипузырная терапия

\section{1. КЛАССИФИКАЦИЯ И ОПРЕДЕЛЕНИЕ СТАДИИ}

Стадирование рака мочевого пузыря (РМП) по системе TNM и группировка по стадиям представлены в табл. 1 и 2. Классификация применима только для рака; папиллома исключается. Гистологическое или цитологическое подтверждение диагноза обязательно.

T - первичная опухоль. Индекс $(\mathrm{m})$, добавленный к категории «Т», указывает на множественные опухоли. Индекс (is) может быть добавлен к любой категории «Т» для указания ассоциации с CIS.

$\mathbf{N}$ - регионарные лимфатические узлы. Регионарными лимфатическими узлами являются лимфатические узлы малого таза, расположенные ниже бифуркации общих подвздошных артерий, с включением лимфатических узлов вдоль подвздошных артерий.

М-отдаленные метастазы.

Таблица 1. Классификация рака мочевого пузыря по системе TNM (8-е издание, 2017 г.)

\begin{tabular}{|c|c|}
\hline $\begin{array}{l}\text { Категории } \\
\text { T, N, M }\end{array}$ & Описание распространения опухоли \\
\hline Та & Неинвазивная папиллярная карцинома \\
\hline Tis & Уротелиальная CIS: «плоская опухоль» \\
\hline T1 & Слизистая до Lamina propria (субэпителиальная соединительная ткань) \\
\hline $\mathrm{T} 2$ & Мышцы мочевого пузыря \\
\hline • T2a & Поверхностный мышечный слой (внутренняя половина мышц) \\
\hline$\cdot \mathrm{T} 2 \mathrm{~b}$ & Глубокий мышечный слой (наружная половина мышц) \\
\hline T3 & Перивисцеральное распространение \\
\hline • ТЗа & Микроскопическое \\
\hline$\cdot$ - T3b & Макроскопическое (экстрапузырная масса) \\
\hline T4 & Предстательная железа, семенные пузырьки, матка, влагалище, стенка таза, брюшная стенка \\
\hline •T4a & Предстательная железа, семенные пузырьки, матка, влагалище \\
\hline$\cdot$ - T4b & Стенка таза, брюшная стенка \\
\hline
\end{tabular}




\begin{tabular}{|l|l|}
\hline $\begin{array}{l}\text { Kaтегории } \\
\text { T, N, M }\end{array}$ & Описание распространения опухоли \\
\hline N1 & $\begin{array}{l}\text { Одиночный (перивезикальный, запирательный, внутренний и наружный подвздошный } \\
\text { или крестцовый) лимфоузел } \\
\text { Множественные (перивезикальный, запирательный, внутренний и наружный подвздошный } \\
\text { N3 }\end{array}$ \\
M1 & $\begin{array}{l}\text { Общие подвздошные лимфоузлы } \\
\text { Отдаленные метастазы } \\
\text { Отдаленные метастазы, ограниченные лимфатическими узлами выше уровня общей } \\
\text { подвздошной артерии } \\
\text { Отдаленные не лимфогенные метастазы }\end{array}$ \\
\hline
\end{tabular}

\section{Степень дифференцировки опухоли (G):}
LG - низкая степень
$\mathrm{HG}$ - высокая степень
GX - степень дифференцировки опухоли не может быть установлена;
$\mathrm{G} 1$ - высокодифференцированная опухоль;
G2 - умеренно дифференцированная опухоль;
G3 - низкодифференцированная/недифференцированная опухоль.

Таблица 2. Группировка рака мочевого пузыря по стадиям

\begin{tabular}{|c|c|c|c|}
\hline Стадия & $T$ & $N$ & $M$ \\
\hline $0 \mathrm{a}$ & Ta & NO & Mo \\
\hline Ois & Tis & NO & MO \\
\hline I & T1 & NO & MO \\
\hline II & T2a, b & No & Mo \\
\hline \multirow[t]{3}{*}{ IIIA } & T3a, b & NO & MO \\
\hline & T4a & No & MO \\
\hline & T1-4a & N1 & MO \\
\hline IIIB & T1-4a & N2, N3 & MO \\
\hline \multirow[t]{2}{*}{ IVA } & T4b & любое N & MO \\
\hline & Любое & любое N & M1a \\
\hline IVB & Любое & любое N & M1b \\
\hline
\end{tabular}




\section{2. НЕМЫШЕЧНО-ИНВАЗИВНЫЙ РАК МОЧЕВОГО ПУЗЫРЯ (TA, T1)}

\section{1. Диагностика}

- Сбор анамнеза: наличие гематурии

- Общий анализ крови с подсчетом лейкоцитарной формулы и количества тромбоцитов

- Биохимический анализ крови с определением показателей функции печени, почек, уровня ЩФ

- Общий анализ мочи

- В/в урография - предпочтительный метод выделительная КТ или МРТ урография (особенно в тех случаях, когда опухоль локализуется в области треугольника Льето, имеются множественные очаги или при опухолях высокого риска)

- УзИ органов брюшной полости, малого таза

- Фиброцистоскопия

- ЦИтологическое исследование мочи (позволяет поставить диагноз CIS) CIS и заподозрить уротелиальный рак верхних мочевых путей при отсутствии данных за рак мочевого пузыря)

- Морфологический диагноз устанавливается на основании данных морфологического исследования биоптата, полученного после выполнения трансуретральной резекции (ТУР) мочевого пузыря. Холодная биопсия не дает полной информации. В гистологическом заключении указываются морфологический подтип опухоли, глубина инвазии, степень злокачественности опухоли по шкале ВОЗ 2004 г., лимфоваскулярная инвазия. Важно полное и правильное выполнение биопсии. В гистологическом материале обязательно должен присутствовать подлежащий мышечный слой. Его отсутствие будет свидетельствовать о невозможности точного определения стадии заболевания.

\section{2. Лечение немышечно-инвазивного рака мочевого пузыря}

Основным методом лечения является ТУР мочевого пузыря. Адъювантная лекарственная терапия проводится в дополнение к ТУР и позволяет снизить риск рецидива болезни. План адъювантной лекарственной терапии основывается на принадлежности опухоли к одной из групп риска (табл. 3).

Таблица 3. Группы риска при раке мочевого пузыря

\begin{tabular}{|l|l|}
\hline Группы риска & Характеристики опухоли \\
\hline Низкий & $\begin{array}{l}\text { Первичная солитарная опухоль Ta, G1' (папиллярно-уротелиальная неоплазия с низким } \\
\text { злокачественным потенциалом (pUNLMp), папиллярно-уротелиальная карцинома } \\
\text { низкой степени (LG)), <3 см, без CIS }\end{array}$ \\
\hline Промежуточный & Все опухоли, не попадающие в категории низкого и высокого риска \\
\hline
\end{tabular}




\begin{tabular}{|c|c|}
\hline Группы риска & Характеристики опухоли \\
\hline Высокий & $\begin{array}{l}\text { Наличие любого из следующих факторов: } \\
\text { - } \mathrm{T1}(\mathrm{G} 2) \\
\text { - } \mathrm{G} 3^{2} \\
\text { - } \mathrm{CIS} \\
\text { - } \\
\text { множественные и рецидивные опухоли > } 3 \text { CM, Ta G1G2/LG (все факторы должны } \\
\text { быть представлены) }\end{array}$ \\
\hline Очень высокий & $\begin{array}{l}\text { Уровень инвазии рT1G3 с CIS; множественные рецидивные опухоли больших размеров; } \\
\text { pT1G3 с CIS в простатическом отделе уретры; редкие гистологические варианты } \\
\text { опухоли с неблагоприятным прогнозом; опухоли T1 с лимфоваскулярной инвазией }\end{array}$ \\
\hline
\end{tabular}

1 Комбинация G1 и G2;

2 Комбинация некоторых G2 и всех G3.

Однократное внутрипузырное введение химиопрепарата, по данным мета-анализов, позволяет снизить риск рецидива на 11,7-13\%. В качестве противоопухолевого средства для этой цели предпочтительно использовать митомицин С в дозе 40 мг в 40 мл физиологического раствора хлорида натрия. Первая инстилляция - в течение 6 часов после выполнения ТУР. Экспозиция - 1час.

Дополнительная адъювантная внутрипузырная терапия вакциной ВСС показана больным промежуточного и высокого риска, что позволяет снизить риск рецидива болезни на $44 \%$ по сравнению с ТУР без адъювантной лекарственной терапии. В исследованиях с поддерживающим введением ВСС было отмечено снижение частоты рецидива на $32 \%$ в сравнении с митомицином С (рис. 1).

Первые инстилляции проводятся через 3-4 нед. после ТУР вакциной для лечения рака мочевого пузыря БЦЖ: 50-100 мг в 50 мл физиологического раствора хлорида натрия. Оптимальным режимом внутрипузырного введения вакцины БЦЖ являются 6 еженедельных инстилляций с последующим переходом на поддерживающую терапию:

- при промежуточном риске рецидива: 3 еженедельных введения препарата на 3, 6 и 12-м месяцах;

- при высоком риске рецидива: 3 еженедельных введения препарата на 3, 6, 12, 18, 24, 30 и 36-м месяцах.

Противопоказано проведение внутрипузырной инстилляции вакцины для лечения рака мочевого пузыря БЦЖ в следующих случаях:

- в течение первых 2 недель после ТУр;

- пациентам с макрогематурией;

- после травматичной катетеризации;

- пациентам с наличием симптомов инфекции мочевого пузыря;

- пациентам с выраженной дизурией.

Наличие лейкоцитурии или асимптоматической бактериурии не является противопоказанием для проведения БЦЖ-терапии, в этих случаях нет необходимости в проведении антибиотикопрофилактики 


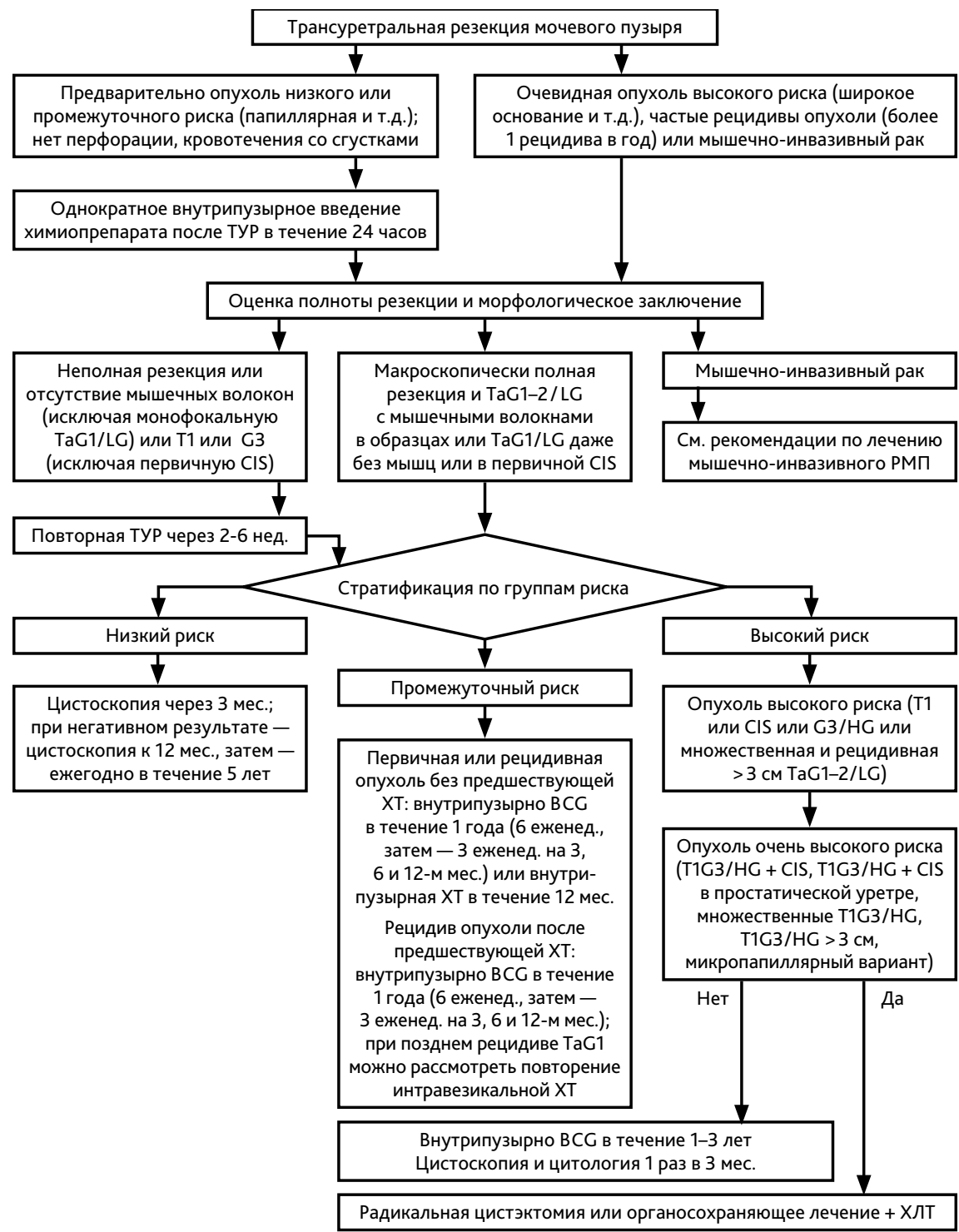

Рисунок 1. Алгоритм лечения и последующего наблюдения больных мышечно-неинвазивным раком мочевого пузыря. 
Необходимо учитывать возможные осложнения внутрипузырного введения вакцины БЦЖ и дальнейшей лечебной тактики (табл. 4). Частота БЦЖ инфекций после БЦЖ инстилляций может составлять $1 \%$.

Таблица 4. Локальные осложнения, индуцированные внутрипузырной иммунотерапией вакциной БЦЖ

\begin{tabular}{|c|c|c|c|}
\hline $\begin{array}{l}\text { Мочеполовые } \\
\text { осложнения }\end{array}$ & Инициальная терапия & $\begin{array}{l}\text { Вспомогательное } \\
\text { лечение }\end{array}$ & Адаптация БЦЖ \\
\hline $\begin{array}{l}\text { Цистит (непереносимое } \\
\text { или болезненное } \\
\text { опорожнение мочевого } \\
\text { пузыря > } 48 \text { часов) }\end{array}$ & $\begin{array}{l}\text { Феназопиридина } \\
\text { гидрохлорид } \\
200 \text { мг×3 раза в день } \\
\text { или НПВС }\end{array}$ & $\begin{array}{l}\text { Назначение антибакте- } \\
\text { риальных препаратов } \\
\text { в случае диагностики } \\
\text { бактериального цистита }\end{array}$ & $\begin{array}{l}\text { Воздержаться от } \\
\text { введения до разрешения } \\
\text { симптомов и заверше- } \\
\text { ния антибактериальной } \\
\text { терапии }\end{array}$ \\
\hline $\begin{array}{l}\text { Контрактура мочевого } \\
\text { пузыря }\end{array}$ & $\begin{array}{l}\text { Гидродистенция } \\
\text { мочевого пузыря }\end{array}$ & $\begin{array}{l}\text { Системные стероиды. } \\
\text { В исключительных } \\
\text { случаях аугментация } \\
\text { мочевого пузыря } \\
\text { или цистэктомия }\end{array}$ & $\begin{array}{l}\text { Прекратить введение } \\
\text { для увеличения емкости } \\
\text { мочевого пузыря }\end{array}$ \\
\hline $\begin{array}{l}\text { Изъязвление мочевого } \\
\text { пузыря }\end{array}$ & $\begin{array}{l}300 \text { мг изониазида } \\
\text { и } 600 \text { мг рифампицина } \\
\text { ежедневно в течение } \\
6 \text { месяцев }\end{array}$ & Нет & $\begin{array}{l}\text { Воздержаться от } \\
\text { введения до разрешения } \\
\text { очагов в мочевом пузыре } \\
\text { и получения БЦж- } \\
\text { негативной мочи }\end{array}$ \\
\hline $\begin{array}{l}\text { Гранулематозный } \\
\text { баланит }\end{array}$ & $\begin{array}{l}\text { Различные комбинации } \\
\text { изониазида, этамбутола, } \\
\text { рифампицина от } 6 \text { до } \\
12 \text { месяцев }\end{array}$ & Нет & $\begin{array}{l}\text { Воздержаться от } \\
\text { введения до разрешения } \\
\text { очагов }\end{array}$ \\
\hline $\begin{array}{l}\text { Туберкулёзный } \\
\text { эпидидимоорхит }\end{array}$ & $\begin{array}{l}300 \text { мг изониазида } \\
\text { и } 600 \text { мг рифампицина } \\
\text { ежедневно в течение } \\
\text { 3-6 месяцев }\end{array}$ & $\begin{array}{l}\text { Для изониазид } \\
\text { резистентных - фторо- } \\
\text { хинолоны или } \\
\text { антитуберкулёзные } \\
\text { аминогликозиды; } \\
\text { для очагов, рефрактер- } \\
\text { ных к антитуберкулёз- } \\
\text { ной терапии, ревизия } \\
\text { мошонки и эпидидимо- } \\
\text { орхиэктомия }\end{array}$ & Полная отмена БЦЖ \\
\hline $\begin{array}{l}\text { Симптоматический } \\
\text { простатит }\end{array}$ & $\begin{array}{l}300 \text { мг изониазида } \\
\text { и } 600 \text { мг рифампицина } \\
\text { ежедневно в течение } \\
\text { 3-6 месяцев }\end{array}$ & $\begin{array}{l}\text { Антибиотики } \\
\text { (фторхинолоны), если } \\
\text { необоходимо; хирурги- } \\
\text { ческое дренирование } \\
\text { абсцессов; биопсия, } \\
\text { если нет улучшения } \\
\text { на фоне лекарственной } \\
\text { терапии }\end{array}$ & Полная отмена БЦЖ \\
\hline
\end{tabular}




\begin{tabular}{|l|l|l|l|}
\hline $\begin{array}{l}\text { Мочеполовые } \\
\text { осложнения }\end{array}$ & $\begin{array}{l}\text { Вспомогательное } \\
\text { лечение }\end{array}$ & Адаптация Бцж \\
\hline Уретральная обструкция & $\begin{array}{l}\text { З00мг изониазида } \\
\text { и 600мг рифампицина } \\
\text { ежедневно в течение } \\
\text { 3-6 месяцев }\end{array}$ & $\begin{array}{l}\text { Установка временного } \\
\text { дренажа (уретральное } \\
\text { стентирование или чрес- } \\
\text { кожная нефростомия) } \\
\text { при гидронефрозе } \\
\text { несмотря на консерва- } \\
\text { тивное лечение }\end{array}$ & $\begin{array}{l}\text { Прекратить введение } \\
\text { в случае появления } \\
\text { возобновить после } \\
\text { разрешения осложнения }\end{array}$ \\
\hline Инфекция почки & $\begin{array}{l}\text { З00мг изониазида, } \\
600 \text { мг рифампицина } \\
\text { и 1200мг этамбутола } \\
\text { ежедневно в течение } \\
6 \text { месяцев }\end{array}$ & $\begin{array}{l}\text { Биопсия при отсутствии } \\
\text { ответа на лекарственное } \\
\text { лечение }\end{array}$ & Полная отмена БЦж \\
\hline
\end{tabular}

Таблица 5. Системные осложнения, индуцированные внутрипузырной иммунотерапией вакциной БЦЖ

\begin{tabular}{|c|c|}
\hline Артралгия и/или артриты & $\begin{array}{l}\text { Лечение с помощью неспецефических противовоспалительных средств; } \\
\text { при отсутствии эффекта или частичном ответе - назначение кортико- } \\
\text { стероидов, хинолонов в высоких дозах или противотуберкулёзных } \\
\text { препаратов }\end{array}$ \\
\hline $\begin{array}{l}\text { Персистирующая лихорадка } \\
\text { (>38.5으 в течение } \\
>48 \text { часов) }\end{array}$ & $\begin{array}{l}\text { Полная отмена БЦж. } \\
\text { Немедленное обследование: посев мочи, анализы крови, рентгенография } \\
\text { органов грудной клетки. } \\
\text { Попытка лечения более чем двумя антимикробными препаратами } \\
\text { в процессе проведения диагностических процедур. } \\
\text { Консультация инфекциониста }\end{array}$ \\
\hline БЦЖ сепсис & $\begin{array}{l}\text { Профилактика: начало внутрипузырного введения БЦЖ не ранее } 2 \text { недель } \\
\text { после ТУР (в отсутствие симптомов гематурии). } \\
\text { Полная отмена БЦЖ. } \\
\text { Для тяжёлой инфекции: } \\
\text { • хинолоны в высоких дозах или изониазид, рифампицин и этамбутол } \\
\text { 1,2 г ежедневно в течение } 6 \text { месяцев; } \\
\text { - раннее назначение ГКС в высоких дозах в течение всего периода } \\
\text { существования симптомов сепсиса; } \\
\text { - рассмотреть эмпирическое назначение неспецифических антибактери- } \\
\text { альных препаратов для лечения грам-негативных бактерий и/или } \\
\text { Enterococсus }\end{array}$ \\
\hline Аллергические реакции & $\begin{array}{l}\text { Антигистаминные и противовоспалительные средства. } \\
\text { Рассмотреть назначение хинолонов в высоких дозах или изониазида } \\
\text { и рифампицина при наличии симптомов. } \\
\text { Отсрочить терапию до разрешения симптомов }\end{array}$ \\
\hline
\end{tabular}

Критериями отсутствия эффекта БЦЖ терапии являются:

1. Появление мышечно-инвазивной карциномы

2. БЦЖ-рефрактерность:

- выявление опухоли T1G3 к 3-му месяцу лечения; 
- выявление опухоли ТаG3 к 3-му месяцу лечения и/или 6-му месяцу после реиндукции или 1 курса поддерживающей терапии;

- выявление CIS (без папиллярной опухоли) к 3-му месяцу лечения и сохранение ее к 6 месяцу после реиндукции или 1 курса поддерживающей терапии. При выявлении CIS на 3-м месяце лечения дополнительное введение БЦЖ может обеспечить полный ответ более чем в $50 \%$ случаев;

- появление G3 опухоли в процессе поддерживающей терапии БЦЖ;

3. БЦЖ рецидивирующая опухоль:

- рецидив G3 после завершения БЦЖ терапии независимо от первоначального ответа;

4. БЦЖ не ответившая опухоль:

- БЦЖ рефрактерность или T1 Ta/G3 рецидив в течение 6 месяцев после завершения лечения БЦЖ или развитие CIS в течение 12 месяцев после завершения адекватной терапии БЦЖ;

5. Непереносимость БЦЖ.

В случае отсутствия эффекта на проведение инстилляций БЦЖ рекомендовано выполнение цистэктомии. Для пациентов, которые не являются кандидатами для радикальной цистэктомии, рекомендовано проведение терапии пембролизумабом 200 мг в/в 1 раз в 3 недели до неприемлемой токсичности или прогрессирования болезни; в случае отсутствия прогрессии опухоли - в течение 24 месяцев. В исследовании KEYNOTE - 057 полная резорбция опухоли отмечалась у $41 \%$ больных, медиана продолжительности ответа составила 16,2 мес.; 46\% больных с ответом опухоли на лечение сохраняли полный ответ в течение 12 месяцев.

\section{3. Наблюдение}

Наблюдение после лечения имеет целью раннюю диагностику рецидива и различается в зависимости от степени риска развития рецидива:

- низкий риск рецидива: в первый год после ТУР - цистоскопия через 3 и 12 мес., далее - ежегодно в течение 5 лет, затем - по клиническим показаниям;

- умеренный риск рецидива: в первый год после ТУР - цистоскопия, цитологическое исследование мочи через 3, 6 и 12 мес., во второй год - каждые 6 мес., далее - ежегодно в течение 5 лет, затем - по клиническим показаниям;

- высокий риск рецидива: в первый год после ТУР - цистоскопия, цитологическое исследование мочи через 3, 6 и 12 мес., КТ выделительная урография - через 12 мес., во второй год - цистоскопия каждые 6 мес., далее - ежегодно в течение 5 лет, затем - по клиническим показаниям, ретроградная пиелография - каждые 12-14 мес. в течение 10 лет. 


\section{3. МЫШЕЧНО-ИНВАЗИВНЫЙ ЛОКАЛИЗОВАННЫЙ РАК МОЧЕВОГО ПУЗЫРЯ СТАДИИ II (Т2NОМО) И СТАДИИ IIIА (T3-T4ANO, T1-T4AN1MO)}

\section{1. Диагностика}

Сбор анамнеза:

- Общий анализ крови с подсчетом лейкоцитарной формулы и количества тромбоцитов

- Биохимический анализ крови с определением показателей функции печени, почек, уровня ЩФ

- Общий анализ мочи

- В/в КТ урография (при невозможности - в/в урография)

- Фиброцистоскопия

- УзИ органов брюшной полости, малого таза; КТ/МРТ органов брюшной полости, малого таза с в/в контрастированием (лимфатические узлы малого таза > 8 мм и абдоминальные узлы >10 мм при измерении наименьшего диаметра следует относить к патологически увеличенным)

- R-графия органов грудной клетки; КТ органов грудной клетки

- ТУР мочевого пузыря

- Сцинтиграфия костей и МРТ головного мозга выполняются при наличии симптомов, указывающих на возможное наличие опухолевых очагов в этих органах

- Рутинное использование ПЭТ-КТ не рекомендуется.

КТ и МРТ могут быть использованы для оценки локальной инвазии, но не позволяют точно установить наличие микроскопической инвазии перивезикальной жировой клетчатки для проведения дифференциальной диагностики между Т2 и ТЗа стадиями. Главной целью КТ или МРТ является диагностика болезни в стадии ТЗЬ и выше и оценка состояния тазовых лимфатических узлов, а также других органов для исключения висцеральных метастазов. МРТ исследование обладает более высоким контрастным разрешением для мягких тканей, чем КТ. Точность МРТ при стадировании первичной опухоли выше на 10-33\%, чем КТ.

\section{2. Лечение}

\subsection{1. Общие принципы лечения мышечно-инвазивного рака мочевого пузыря}

Радикальная цистэктомия с тазовой лимфодиссекцией в сочетании или без неоадъювантной ХТ является наиболее часто используемым во многих странах вариантом лечения при T2-4аNOMO. Органосохраняющий подход с сочетанной ХлТ является опцией для пациентов, которые не являются кандидатами для радикальной цистэктомии или для тех, кто желает сохранить мочевой пузырь и/или избежать эректильную дисфункцию (среди мужчин). Оба метода считаются стандартными альтернативными вариантами 
лечения. Радикальная цистэктомия и облучение мочевого пузыря с сочетанной XТ обеспечивают 5-летнюю выживаемость около $50 \%$.

Роль адъювантной ХT не доказана из-за отсутствия крупных валидирующих клинических исследований, однако адъювантная ХТ может быть использована после радикальной цистэктомии при рТ3-Т4 или рN +у пациентов, которым не была проведена неоадъювантная XТ, а также после органосохраняющего лечения с сочетанной ХЛТ. В настоящее время адъювантная иммунотерапия не является стандартом лечения.

Роль адъювантной ЛТ после радикальной цистэктомии не доказана и в настоящее время не рекомендована к использованию. Неоадъювантная лТ не влияет на выживаемость и также не должна проводиться перед радикальной цистэктомией.

Общепринятым подходом для пациентов с отсутствием противопоказаний к цисплатин-содержащей ХТ в настоящее время является проведение неоадъювантной ХТ (перед радикальной цистэктомией), которая улучшает 5-летнюю выживаемость на 5-8\% в абсолютном исчислении и снижает риск смерти на $16 \%$. Данные комбинированных исследований показывают, что наилучшие результаты достигаются в подгруппе пациентов с Т2b-Т3b. Оптимальным следует считать проведение 3-4 циклов XТ с использованием платиносодержащих схем (MVAC, CG) при сохранной функции почек (клиренс креатинина > 60 мл/мин.) и общем удовлетворительном состоянии. Применение 3-недельного СС не уступает по эффективности 4-недельному режиму в связи с более высокой плотностью дозы (за счёт менее частой необходимости редукции дозы препаратов) и сопровождается меньшей частотой тромбоцитопений. Рекомендуемые режимы нео-и адъювантной ХТ РМП представлены в табл. 6.

Таблица 6. Рекомендуемые режимы нео-и адъювантной ХТ рака мочевого пузыря

\begin{tabular}{|c|c|}
\hline Название & Режим введения химиопрепаратов \\
\hline CG & $\begin{array}{l}\text { Цисплатин } 70 \text { мг/м² в/в в 1-й день + гемцитабин } 1000 \text { мг/м² в/в в 1-й, 8-й и 15-й дни } \\
\text { каждые } 4 \text { нед. }\end{array}$ \\
\hline $\mathrm{CG}^{1}$ & Цисплатин 70 мг/м² в/в в 1-й день + гемцитабин 1000 мг/м² в/в в 1-й, 8-й дни каждые 3 нед. \\
\hline MVAC & 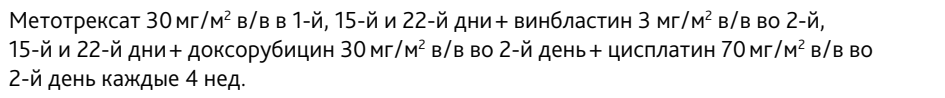 \\
\hline $\begin{array}{l}\text { MVAC } \\
\text { (высокие } \\
\text { дозы) }\end{array}$ & $\begin{array}{l}\text { Метотрексат } 30 \text { мг/м² в/в в 1-й день + винбластин } 3 \text { мг/м² в/в во 2-й день + доксорубицин } \\
30 \text { мг/м² в/в во 2-й день + цисплатин } 70 \text { мг/м² в/в во 2-й день + филграстим } 5 \text { мкг/кг } \\
\text { п/к в 4-10-й дни каждые } 2 \text { нед. }\end{array}$ \\
\hline $\mathrm{CMV}^{1}$ & $\begin{array}{l}\text { Метотрексат } 30 \text { мг/м² в/в в 1-й, 8-й дни + винбластин } 4 \text { мг/м² в/в в 1-й, 8-й дни + цисплатин } \\
100 \text { мг/м² в/в во 2-й день + кальция фолинат } 15 \text { мг в/в или перорально каждые } 6 \text { часов } \\
\text { №4 во 2-й и 9-й дни каждые } 4 \text { нед. }\end{array}$ \\
\hline
\end{tabular}

1 Режим/nрепарат зарегистрирован в РФ, но не входит в клинические рекомендации, одобренные Минздравом РФ.

Не рекомендуется проводить неоадъювантную ХТ с карбоплатином, так как в настоящее время отсутствуют данные об эффективности этих комбинаций. Имеются ограниченные ретроспективные данные об эффективности неоадъювантной ХT у больных не уротели- 
альной карциномой. Пациенты с нейроэндокринной опухолью имели улучшение общей выживаемости от проведения ХТ цисплатином и этопозидом, в то время как в случаях микропапиллярной и саркоматоидной дифференциации и аденокарциномы было обнаруженоснижение частоты внеорганных метастазов, но не отмечено улучшения общей выживаемости. Пациенты с плоскоклеточной карциномой не получали пользы от неоадъювантной ХT. Органосохраняющий подход на базе ЛТ малого таза является международно принятой альтернативой радикальной цистэктомии. Поскольку после органосохраняющего лечения вероятность местного рецидива достигает $30 \%$, пациенты должны наблюдаться каждые 2-3 мес. с выполнением цистоскопии и радикальной сальважной («спасительной») цистэктомии в случае рецидива мышечно-инвазивного РМП. При таком подходе органосохраняющее лечение не должно увеличить риск смертности от РМП. Минусом сальважной цистэктомии является ограничение формирования ортотопических континентныхмочевых резервуаров. Для наибольшей эффективности органосохраняющее лечение включает максимальную ТУР (резекция сквозь уровень мышцы до жирового покроя и максимальная резекция всей видимой опухоли) с последующей сочетанной ХлТ либолТ с использованием модификаторов гипоксии (карбоген/никотинамид). С учетом экстраполяции результатов неоадъювантной ХТ при радикальной цистэктомии, неоадъювантная ХТ также возможна до органосохраняющего лечения с лТ/ХЛТ.

Таблица 7. Рекомендуемые режимы одновременной химиолучевой терапии рака мочевого пузыря

\begin{tabular}{|c|c|}
\hline Режим химиотерапии & Режим лучевой терапии \\
\hline $\begin{array}{l}\text { 5-фторурацил } 500 \text { мг/м²/сут. в/в в 1-5-й и 16-20-й дни+ } \\
\text { митомицин С } 12 \text { мг/м² в/в в 1-й день }{ }^{1}\end{array}$ & $\begin{array}{l}\text { СОД } 55 \text { Гр (20 фракций) или } 64 \text { Гр } \\
\text { (32 фракции) }\end{array}$ \\
\hline Цисплатин 100 мг/м² в/в в 1-й, 15-й, 29-й дни ${ }^{1}$ & СОД 60-66 Гр (30-33 фракции), 6 нед. \\
\hline Цисплатин 40 мг/м² в/в еженедельно, 6 введений ${ }^{1}$ & СОД 60-66 Гр (30-33 фракции), 6 нед. \\
\hline $\begin{array}{l}\text { Гемцитабин } 27 \text { мг/м² в/в в 1-й и 4-й дни каждой недели (интервал } \\
\text { не менее } 72 \text { часов) }\end{array}$ & $\begin{array}{l}\text { СОД 60-66 Гр (30-33 фракции), более } \\
4 \text { нед. }\end{array}$ \\
\hline 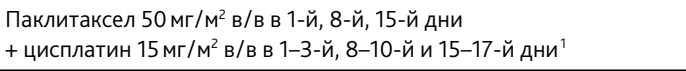 & ЛТ два раза в день, СОД 64,3 Гр \\
\hline $\begin{array}{l}\text { Цисплатин } 15 \text { мг/м² в/в в 1-3-й, 8-10-й и 15-17-й дни } \\
+ \text { 5-фторурацил } 400 \text { мг/м² в/в в 1-3-й, 8-10-й и 15-17-й дни }\end{array}$ & ЛТ два раза в день, СОД 64,3 Гр \\
\hline
\end{tabular}

1 Режим/nрепарат зарегистрирован в РФ, но не входит в клинические рекомендации, одобренные Минздравом РФ.

Замена цисплатина на карбоплатин не рекомендуется из-за отсутствия доказательств равной эффективности. Режим модификации гипоксии при одновременной лТ РМП: карбоген (2\% $\mathrm{CO}_{2}$ и 98\% О 2 ) со скоростью 15 л/мин., начинается за 5 мин до лт и продолжается в течение ЛТ. Никотинамид назначается в дозе 60 мг/кг перорально за 1,5-2 часа до фракции ЛТ. У пациентов, имеющих токсические реакции (тошнота, головные боли), доза никотинамида может быть редуцирована до 40 мг/кг или введение препарата может быть прекращено. 


\section{3. Наблюдение}

Наблюдение после лечения имеет целью раннюю диагностику рецидива и способствует выявлению больных, которым могут быть выполнены «спасительные» варианты терапии.

3.3.1. После радикальной цистэктомии: клинический осмотр, общий и биохимический анализы крови; КТ органов грудной клетки (или рентгенография органов грудной клетки) брюшной полости, малого таза должны проводиться каждые 3-6 месяцев в течение первых 2 лет, далее - в течение последующих 3 лет ежегодно, в последующие 5 лет показано ежегодное узи почек.

3.3.2. Для пациентов после органосохраняющего лечения: клинический осмотр, общий и биохимический анализы крови, цистоскопия; КТ органов брюшной полости, малого таза, грудной клетки (или рентгенография органов грудной клетки) должны проводиться каждые 3 мес. в течение первых 2 лет, затем каждые 6 месяцев последующие 2 года, далее - в течение 5 лет ежегодно (цистоскопия - каждые 6 мес.), в последующие 5 лет показано ежегодное УзИ почек.

\section{4. МЕСТНО-РАСПРОСТРАНЕННЫЙ РАК МОЧЕВОГО ПУЗЫРЯ СТАДИЯ IIВ (Т1-T4А N2-3 МО) ИЛИ IVA (Т4В No-3 M0, T1-4B No-3 M1A)}

При РМП стадии IIIB и IVA рекомендуется либо сочетанная ХЛТ, либо ХT с последующей оценкой ответа на ХT с выполнением консолидирующей локальной терапии (радикальной цистэктомии либо ХЛТ при полном, либо частичном ответе на ХТ). Выполнение первичной радикальной цистэктомии не рекомендуется. Рекомендуемые режимы ХЛТ представлены в табл. 5 .

\section{5. МЕТАСТАТИЧЕСКИЙ РАК МОЧЕВОГО ПУЗЫРЯ СТАДИЯ IVB (T1-4B, N0-3, M1B)}

\section{1. Лечение}

Лечение диссеминированной болезни является паллиативным и направлено на улучшение качества жизни и увеличение ее продолжительности. Основным методом является лекарственная терапия. В ряде случаев, встречается олигометастатическая болезнь, при которой выявляется до 5 метастазов в различных органах, синхронных с первичной опухолью или возникающих как метахронный рецидив болезни. Благоприятными факторами являются одиночное поражение или появление рецидива более чем через 36 месяцев после лечения первичной опухоли. При солитарных метастазах возможно использование метода локального контроля первичной опухоли и метастатических очагов. Метод локального контроля - хирургическая резекция, лТ, РЧА - должен 
определяться на междисциплинарном консилиуме, исходя из экспертизы лечащих врачей и предпочтений пациентов.

Выбор варианта лечения определяется общим состоянием пациента и выделительной функции почек (рис. 2). Платиносодержащая комбинированная XT (MVAC, цисплатин +гемцитабин) является стандартной и способствует увеличению продолжительности жизни больных до 14, 8 и 13,8 мес. соответственно. Более низкая токсичность комбинации «цисплатин +гемцитабин» способствует более частому применениюе в качестве стандартного режима. Высокодозный MVAC с использованием Г-КСФ обеспечивает бо́льшую плотность дозы, менее токсичен, чем стандартный MVAC, и обеспечивает бо́льшую частоту полных ответов и 2-летнюю выживаемость с пограничной статистически значимой редукцией в риске прогрессии и смерти к 5 годам наблюдения.

Интенсификация лечения за счёт добавления паклитаксела к цисплатину и гемцитабину не привела к значимому улучшению общей выживаемости. Однако частота общего ответа опухоли на лечение была на $12 \%$ выше в группе трехкомпонентного режима в сравнении со стандартной комбинацией, была отмечена также тенденция к улучшению общей выживаемости (15,8 против 12,7 мес. соответственно). На основании сравнения эффективности и токсичности различных режимов стандартными подходами в первой линии XT метастатического рака мочевого пузыря следует считать использование режимов CG и ddMVAC.

Несколько исследований II фазы, посвященных сравнению карбоплатина и цисплатина, указывают на более низкую эффективность режимов с карбоплатином. Карбоплатин-содержащая ХT не является эквивалентной комбинациям на основе цисплатина и не должна рассматриваться в качестве замены или стандарта (исключение может быть сделано для отдельных клинических ситуаций, при которых лечение цисплатином противопоказано).

После завершения 4-6 циклов ХТ «гемцитабин +цисплатин/карбоплатин» через 4-10 недель в качестве поддерживающей терапии оптимально использование авелумаба 10 мг/кг 1 раз в 2 недели непрерывно длительно до прогрессирования или неприемлемой токсичности. Это позволяет увеличить медиану продолжительности жизни с 14,3 мес. до 21,4 мес. при лечении авелумабом.

Исследования III фазы IMvigor130, Keynote 361 и DANUBE, проводившие изучение комбинации иммунотерапии (атезолизумаба, пембролизумаба, дурвалумаба с тремелимумабом соответственно) с платиносодержащей химиотерапией в 1-й линии лечения пациентов метастатическим раком мочевого пузыря не продемонстрировали улучшения общей выживаемости в сравнении с XT препаратами платины и в настоящее время пока не рассматриваются в качестве стандартного подхода в І линии лечения.

Более $50 \%$ пациентов с уротелиальным раком не подлежат цисплатин-содержащей ХT. Относительными противопоказаниями для использования цисплатина являются:

- состояние по шкале ЕСОG >1 балла;

- клиренс креатинина <60мл/мин.;

- потеря слуха и периферическая нейропатия >2 ст.;

- сердечная недостаточность III класса по NYHA. 


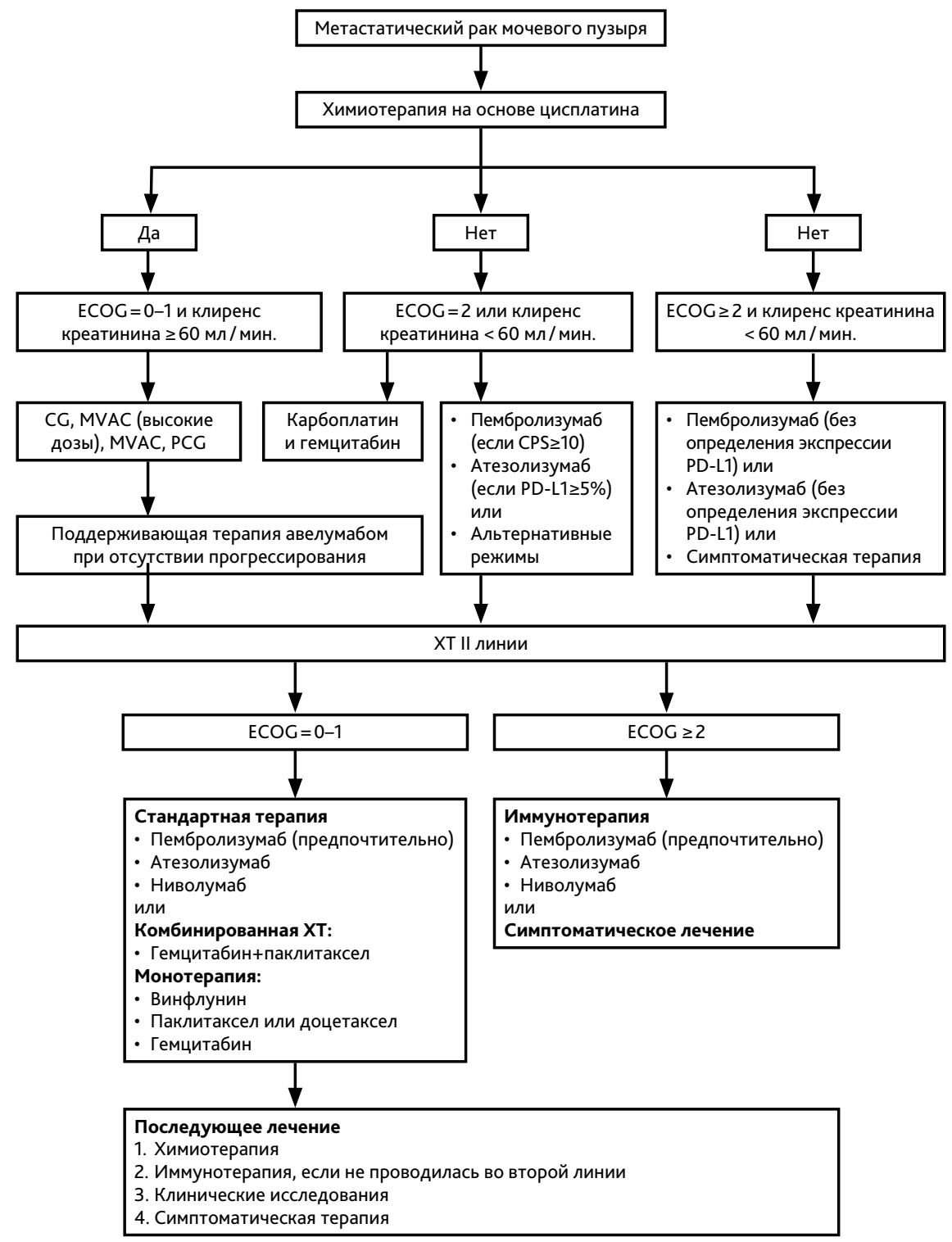

Рисунок 2. Алгоритм лечения пациентов метастатическим раком мочевого пузыря. 
При противопоказаниях к введению цисплатина могут быть использованы комбинации на основе карбоплатина либо монотерапия гемцитабином или таксанами. При противопоказаниях к введению цисплатина у пациентов с положительнойоэкспрессией PD-L1 альтернативой XT являются ингибиторы иммунных контрольных точек - атезолизума6 1200 мг в/в 1 раз в 21 день при экспрессии PD-L1 25\% или пембролизумаб 200 мг в/в 1 раз в 21 день при комбинированном показателе позитивности (Combined Positive Score, CPS) $\geq 10 \%$. Хотя иммунотерапия PD-L1 позитивных пациентов ассоциируется с длительными ремиссиями, частота общего ответа уступает ХТ с включением карбоплатина, а время до прогрессирования и продолжительность жизни не превосходят аналогичные показатели при проведении ХТ с включением карбоплатина.

При противопоказаниях к введению препаратов платины (цисплатина и карбоплатина) ингибиторы контрольных точек иммунного ответа могут быть использованы без определения уровня экспрессии PD-L1. Данное обновление клинических рекомендаций связано с решением FDA и EMA, предписывающим ограничение показаний к применению ингибиторов иммунных контрольных точек в лечении рака мочевого пузыря.

У пациентов с прогрессированием болезни после ранее проведенной XT, не получавших анти-PD1 терапию, назначение пембролизумаба 200 мг в/в 1 день каждые 3 нед. способствует увеличению медианы продолжительности жизни на 3 мес. и частоты объективных ответов на $10 \%$ в сравнении с любым вариантом ХТ по выбору врача вне зависимости от уровня экспрессии PD-L1. В нерандомизированных исследованиях II фазы продемонстрирована эффективность ингибиторов иммунных контрольных точек ниволумаба 3 мг/кг в/в 1 раз в 14 дней и атезолизумаба 1200 мг в/в 1 раз в 21 день. Кроме того, ряд исследований II фазы продемонстрировали схожую умеренную эффективность гемцитабина, паклитаксела, доцетаксела, пеметрекседа во II линии у резистентных к платиносодержащей терапии пациентов (13-28\% общего ответа на лечение). Оптимальный подход у пациентов с прогрессированием болезни на фоне поддерживающей терапии авелумабом пока не определен.

Во II линии возможной стратегией может быть повторное назначение XТ на основе цисплатина у ранее чувствительных к препаратам платины пациентов, если прогрессия наблюдается через 12 и более мес. после I линии цисплатин-содержащей XT. Возможно повторное использование гемцитабина, в том числе комбинации «паклитаксел +гемцитабин». Рекомендуемые режимы ХТ метастатического РМП представлены в табл. 8.

Таблица 8. Рекомендуемые режимы химиотерапии метастатического рака мочевого пузыря

\begin{tabular}{|c|c|}
\hline Название & Режим введения химиопрепаратов \\
\hline CG & $\begin{array}{l}\text { Цисплатин } 70 \text { мг/м² в/в в 1-й день + гемцитабин } 1000 \text { мг/м² в/в в 1-й, 8-й и 15-й дни } \\
\text { каждые } 4 \text { нед. }\end{array}$ \\
\hline $\mathrm{CG}^{1}$ & $\begin{array}{l}\text { Цисплатин } 70 \text { мг/м² в/в в 1-й день + гемцитабин } 1000 \text { мг/м² в/в в 1-й и 8-й дни каждые } \\
3 \text { нед. }\end{array}$ \\
\hline CarboG & $\begin{array}{l}\text { Карбоплатин AUC-4,5 в/в в 1-й день + гемцитабин } 1000 \text { мг/м²/сут. в/в в 1-й и 8-й дни } \\
\text { каждые } 3 \text { нед. }\end{array}$ \\
\hline
\end{tabular}




\begin{tabular}{|c|c|}
\hline Название & Режим введения химиопрепаратов \\
\hline MVAC & 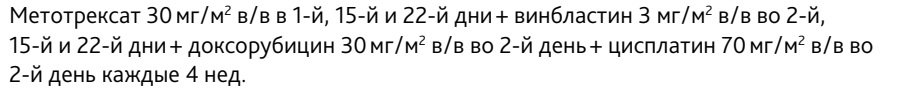 \\
\hline $\begin{array}{l}\text { MVAC (высокие } \\
\text { дозы) }\end{array}$ & 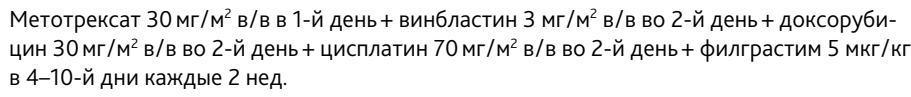 \\
\hline $\mathrm{PCG}^{1}$ & $\begin{array}{l}\text { Паклитаксел } 70 \text { мг/м² в/в в 1-й и 8-й дни + цисплатин } 70 \text { мг/м² в/в в 1-й день + } \\
\text { гемцитабин } 1000 \text { мг/м²/сут. в/в в 1-й и 8-й дни каждые } 3 \text { нед. }\end{array}$ \\
\hline$G P^{1}$ & $\begin{array}{l}\text { Гемцитабин } 2500 \text { мг/м²/сут. в/в в 1-й день + паклитаксел } 150 \text { мг/м² в/в в 1-й день } \\
\text { каждые } 2 \text { нед. }\end{array}$ \\
\hline Винфлунин & 320 мг/м² в/в в 1-й день каждые 3 нед. \\
\hline Гемцитабин ${ }^{1}$ & 1200 мг/м² в/в в 1-й, 8-й, 15-й дни каждые 4 нед. \\
\hline Паклитаксел ${ }^{1}$ & $\begin{array}{l}80 \text { мг/м² в/в в 1-й, 8-й, 15-й дни каждые } 4 \text { нед. или } 175 \text { мг/м² в/в кап. 1-й день каждые } \\
3 \text { нед. }\end{array}$ \\
\hline Доцетаксел ${ }^{1}$ & 75-100 мг/м² в/в в 1-й день каждые 3 нед. \\
\hline Пеметрексед ${ }^{1}$ & $\begin{array}{l}500 \text { мг/м² в/в в 1-й день каждые } 3 \text { нед. + фолиевая кислота 350-1000 мкг перорально } \\
\text { ежедневно + витамин В121000 мкг в/м } 1 \text { раз в } 9 \text { недель }\end{array}$ \\
\hline Атезолизумаб & 840 мг в/в каждые 2 нед. или 1200 мг в/в каждые 3 нед. или 1680 мг в/в каждые 4 нед. \\
\hline Пембролизумаб & 200 мг в/в 1 день каждые 3 нед. \\
\hline Авелума6 ${ }^{1}$ & 10 мг/кг в/в в 1-й день каждые 2 нед. \\
\hline
\end{tabular}

1 Режим/nрепарат зарегистрирован в РФ, но не входит в клинические рекомендации, одобренные Минздравом РФ.

В качестве II линии XT при резистентности к платиносодержащим комбинациям и отсутствии возможности проведения иммунотерапии больным с благоприятными прогностическими характеристиками (состояние по шкале ECOG <2 баллов, гемоглобин >10 г/дл, отсут-

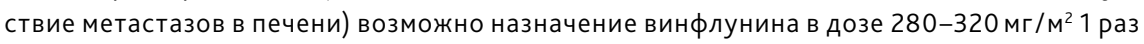
в 3 нед. В рандомизированном исследовании назначение данного препарата в качестве II линии терапии больным метастатическим РМП с благоприятными прогностическими характеристиками увеличивало медиану продолжительности жизни на 2,5 мес. в сравнении с оптимальной поддерживающей терапией.

При оценке эффективности иммунотерапии необходимо учитывать, что псевдопрогрессия практически не встречается при раке мочевого пузыря.

Ретроспективные данные лечения пациентов, прогрессирующих после иммунотерапии, демонстрируют возможность объективного противоопухолевого ответа при последующем проведении им ХT. В связи с этим при выборе дальнейшей тактики лечения следует ориентироваться в большей степени на XT, чем на иммунотерапию.

лТ с паллиативной целью может использоваться для уменьшения симптомов, ассоциированных с опухолевым процессом. 


\section{2. Наблюдение в процессе лечения. Оценка эффекта}

Наблюдение в процессе лечения проводится с целью оценки эффективности и токсичности и включает периодический осмотр и оценку различных симптомов, лабораторных данных и результатов инструментального обследования. Оценку эффекта рекомендуется проводить после каждых 2-3 циклов ХТ с помощью данных общего осмотра, выяснения жалоб и результатов инструментальных методов обследования, выявивших патологиюна этапе первоначальной диагностики. Результаты обследования оцениваются с использованием критериев RECIST 1.1. 